To Maega $\mid$ Jurnal Pengabdian Masyarakat

Februari 2021, Vol.4, No.1, hal. 63-70

$\operatorname{ISSN}(P): 2622-6332 ; \operatorname{ISSN}(E): 2622-6340$

http://www.ojs.unanda.ac.id/index.php/tomaega

\title{
Sosialisasi dan Simulasi Tentang Pemijatan Bayi Untuk Mendukung Tumbuh Kembang Bayi
}

\author{
Indah Yun Diniaty Rosidi ${ }^{1,}$, Lili Purnamasari ${ }^{1}$ \\ ${ }^{1}$ DIII Kebidanan, STIKes Nani Hasanuddin Makassar \\ *Correspondent Email: indahbo73@gmail.com
}

\author{
Article History:
}

Received: 16-11-2020; Received in Revised: 25-11-2020; Accepted: 30-11-2020

DOI: http://dx.doi.org/10.35914/tomaega.v4i1.492

\begin{abstract}
Abstrak
Pijat bayi merupakan terapi sentuh paling tua dan paling populer yang dikenal manusia serta salah satu bentuk stimulasi dini yang sangat penting untuk menunjang tumbuh kembang anak. Di Indonesia pelaksanaan pijat bayi di masyarakat dilakukan oleh dukun bayi, dimana pelaksanaanya hanya pada saat bayi sakit. Pijat bayi akan optimal sebagai stimulasi tumbuh kembang jika dilakukan secara rutin saat sehat, bukan pada saat sakit. Pengabdian ini bertujuan untuk memberikan pemahaman dan praktek tentang pijat bayi kepada masyarakat terkhususnya ibu yang memiliki bayi agar dapat melakukan secara mandiri pijat bayi kepada anaknya. Metode yang digunakan adalah pelatihan dan pendidikan kepada masyarakat dengan sasaran ibu nifas beserta bayinya yang berjumlah 16 orang, dan dilakukan selama 2 hari. Kegiatan pada hari pertama yaitu penyuluhan dengan memberikan pengetahuan tentang pijat bayi dan pengaruhnya terhadap tumbuh kembang bayi, sedangkan hari kedua dilaksanakan pelatian pijat bayi kepada ibu dan bayi dipandu oleh instruktur bersertifikat. Hasil pengabdian menunjukkan ibu memiliki pengetahuan yang baik tentang pijat bayi dan pengaruhnya terhadap tumbuh kembang bayi, serta adanya sikap positif dan mampu melakukan secara mandiri pijat bayi di rumah bahkan enjoy bersama bayinya.
\end{abstract}

Kata Kunci: Pijat Bayi, Baby Spa, Tumbuh Kembang, Bayi

\begin{abstract}
Baby massage is the oldest and most popular touch therapy known to man and one of the most important forms of early stimulation to support a child's growth and development. In Indonesia, the implementation of infant massage in the community is carried out by traditional birth attendants, where it is only implemented when the baby is sick. Baby massage will be optimal as a stimulation for growth and development if it is done regularly when healthy, not when sick. This service aims to provide understanding and practice of infant massage to the community, especially mothers who have babies so that they can independently massage their babies to their children. The method used is training and education to the community with the target of postpartum mothers and their babies totaling 16 people, and is carried out for 2 days. The activity on the first day was counseling by providing knowledge about baby massage and its effect on infant growth and development, while on the second day, training was held for infant massage for mothers and babies guided by certified instructors. The results of this dedication show that mothers have good knowledge about baby massage and its effect on baby growth and
\end{abstract}


[ 64 ] Indah Yun Diniaty Rosidi, dkk / To Maega : Jurnal Pengabdian Masyarakat, Vol.4; No.1; Febrauari 2021

development, as well as a positive attitude and are able to independently massage babies at home and even enjoy them with their babies.

Key Word: Baby Massage, Baby Spa, Growth and Development, Baby

\section{Pendahuluan}

Masalah kesehatan anak merupakan salah satu masalah utama dalam bidang kesehatan yang saat ini terjadi di negara Indonesia. Derajat kesetan anak mencerminkan derajat kesehatan bangsa, sebab anak sebagai generasi penerus bangsa yang memiliki kemampuang yang dapat dikembangkan dalam meneruskan pembangunan bangsa (Dwienda, 2014).

Masa bayi merupakan masa keemasan serta masa kritis dalam pertumbuhan dan perkembangan, sebab pada masa ini bayi sangat peka terhadap lingkungan sekitar. Masa bayi berlangsung sangat cepat dan tidak dapat diulang kembali. Bayi dapat tumbuh dan berkembang dengan sehat jika kebutuhan dasarnya terpenuhi, yaitu asah, asih dan asuh. Kebutuhan asah disebut dengan kebutuhan stimulasi. Pemberian stimulasi perlu diberikan secara dini untuk merangsang dan mengembangkan sedini mungkin kemampuan sensorik, emosional bahkan kognitif bayi/anak yaitu dengan melakukan pijat bayi (Rakhmawati, 2007).

Pijat adalah terapi sentuh paling tua dan paling populer yang dikenal manusia. Pijat adalah seni perawatan kesehatan dan pengobatan yang telah dipraktekkan sejak berabad-abad silam, di seluruh dunia termasuk di Indonesia. Di Indonesia, seni pijat diajarkan secara turun temurun, tanpa diketahui secara jelas bagaimana pijat dan sentuhan dapat secara positif berpengaruh pada tubuh manusia (Roesli, 2001).

Bayi dapat merasakan sensasi sentuhan atau raba sejak dini, sebab kulit adalah reseptor yang terluas dan telah dibuktikan bahwa bayi dapat merasakan sentuhan sejak masa janin atau ketika di dalam rahim ibu. Ujung-ujung saraf pada permukaan kulit akan bereaksi terhadap setiap sentuhan dan selanjutnya akan mengirimkan pesan ke otak melalu jaringan saraf yang berada di sumsum tulang belakang. Sentuhan juga akan merangsang peredaran darah sehingga oksigen segar akan lebih banyak dikirim ke otak dan seluruh tubuh, serta akan menambah energi (Roesli, 2001).

Menurut dr. Utami Roesli (2009), ahli neonatologi Indonesia, terapi sentuh (terutama pijat) menghasilkan perubahan fisilogis (berkaitan dengan zat hidup seperti organ, jaringan atau sel) yang menguntungkan dan dapat diukur secara ilmiah melalui pengukuran kadar cortisol ludah, kadar cortisol plasma secara Radioimunoassay, kadar hormone stress (Chatecholamine) air seni dan pemerikasaan EEG (Electro Enchepalogram).

Orang tua dapat melakukan pijat pada bayi karena akan meningkatkan bounding attachment serta meningkatkan perkembangan sistem saraf otak bayi yang akan membentuk dasar untuk berfikir, merasakan dan belajar. Selain itu pijat 
dapat membuat bayi semakin tenang, sehingga meningkatkan efektivitas tidur bayi dan mengurangi resiko penyakit karena meningkatkan gerak peristaltik usus untuk pencernaan, menstimulasi aktivasi Nervus Vagus untuk perbaikan pernapasan dan memperkuat sistem kekebalan tubuh (Subakti, 2008; Maharani, 2009).

Penemuan ini cukup menjadi alsan untuk dilakukannya pijat bayi secara ruitn guna mempertahan kesehatan bayi itu sendiri. Untuk mendapatkan manfaat yang optimal, pemijatan bayi tidak bisa dilakukan sembarangan, ada cara yang harus diperhatikan, pada bayi usia $0-3$ tahun, gerakan yang dilakukan lebih mendekati usapan-usapan halus, tekanan ringan, dan dengan tekanan, disarankan pemijatan dilakukan sekitar 15 menit, sesuai usia bayi dan waktu yang semakin meningkat (Roesli, 2009).

Di Indonesia, sejarah pemijatan berawal dari nenek moyang masa lampau dan turun temurun hingga sekarang. Pelaksanaan pijat bayi di masyarakat masih dipegang perannya oleh dukun bayi. Keterampilan pijat bayi yang dimiliki dukun bayi berasal dari pengetahuan yang turun temurun tanpa pelatihan khusus serta tidak dapat dipertanggung jawabkan secara ilmiah, sehingga manfaatnya kurang optimal. Selain itu, perilaku masyarakat yaitu memijatkan bayinya ke dukun bayi hanya ketika bayi sedang sakit, padahal pijat bayi akan optimal sebagai stimulasi tumbuh kembang jika dilakukan secara rutin saat sehat, tidak hanya ketika sedang sakit saja. Pada saat ini sedang marak nama "Baby Spa" yaitu pijat bayi yang dilakukan sudah bertujuan untuk stimulasi tumbuh kembang dan dilakukan oleh tenaga yang sudah terlatih, namun biasanya dengan biaya relatif mahal yang tidak terjangkau oleh masyarakat kelas ekonomi menengah ke bawah.

Berdasarkan hal tersebut maka dilaksanakan kegiatan pengabdian kepada masyarakat dalam bentuk sosialisasi dan simulasi tentang pemijatan bayi untuk mendukung tumbuh kembang bayi. Pengabdian masyarakat ini dilakukan untuk memberikan pemahaman dan praktek tentang pijat bayi kepada masyarakat terkhususnya ibu yang memiliki bayi agar dapat melakukan secara mandiri pijat bayi kepada anaknya.

\section{Metode}

Kegiatan pengabdian kepada masyarakat dilaksanakan di BPM Suriyanti, Kota Makassar, Sulawesi Selatan. Metode pelaksanaan kegiatan pengabdian kepada masyarakat $(\mathrm{PKM})$ terbagi dalam beberapa tahap sebagai berikut:

1. Persiapan

a. Persiapan dilakukan mulai dari bulan februari hingga juli 2019

b. Survey lokasi dengan melakukan kunjungan ke lokasi, mitra dan kelompok masyrakat yang akan dijadikan sasaran yaitu di Wilayah kerja BPM Suriyanti

c. Mengumpulkan data-data serta berdiskusi dan berkoordinasi dengan Kepala BPM Suriyanti 
[ 66 ] Indah Yun Diniaty Rosidi, dkk / To Maega : Jurnal Pengabdian Masyarakat, Vol.4; No.1; Febrauari 2021

d. Persiapan bahan administrasi yaitu surat tugas, surat izin melakukan kegiatan

e. Persiapan petugas yaitu pembagian tugas dan tanggung jawab dosen dan mahasiswa yang terlibat dalam PKM

f. Persiapan materi dan media yang akan digunakan dalam kegiatan PKM yaitu Laptop, LCD, Leafet, powerpoint

\section{Pelaksanaan}

Pelaksanaan PKM menggunakan metode pelatihan dan pendidikan masyarakat yaitu melibatkan masyarakat dan mahasiswa selama proses pelaksanaan. Pelaksanaan dilakukan pada tanggal 4-5 Agustus 2019. Adapun kegiatan pelaksanaan yang akan dilaksanakan yaitu sebagai berikut :

a. Penyuluhan

Pada tahap pelaksanaan ini dosen memberikan penyuluhan tentang pijat bayi dan pengaruh pijat bayi terhadap tumbuh kembang bayi.

Penyuluhan dibagi menjadi 2 sesi dengan 2 pemateri.

b. Pelatihan

Pada tahap pelaksanaan ini masyarakat yaitu ibu-ibu melakukan pelatihan atau simulasi pijat bayi yang melibatkan mahasiswa dan dosen serta petugas yang telah bersetifikat Theraphy's Baby

3. Evaluasi

Pada tahap pelaksanaan ini membuat instrument evaluasi untuk mengukur tingkat kepahaman dan kemampuan ibu dalam melaksanakan pijat bayi setelah mendapatkan materi dan pelatihan. Dilaksanakan 19 - 25Agustus 2019 di BPM Suriyanti.

\section{Hasil dan Pembahasan}

1. Persiapan

Pada tahap persiapan dilakukan dengan survei wilayah dimana tim PKM memutuskan untuk melaksanakan PKM di BPM Suriyanti. BPM Suriyanti terkenal dengan pelayanan pijat bayi. Pada kegiatan PKM, dosen melibatkan mahasiswa DIII Kebidanan sebanyak 5 orang yang akan membantu dalam temu konsultasi mitra, identifikasi masalah dan perumusan masalah dalam kegiatan serta penyusunan schedule kegiatan.

Mahasiswa dalam tahap persiapan membantu untuk identifikasi masalah pengetahuan ibu tentang pijat bayi dan keterampilan ibu dalam melakukan pijat bayi. Persiapan petugas yaitu pembagian tugas dan tanggung jawab dosen yaitu sebagai pemateri dan instruktur pijat bayi dan mahasiswa yang terlibat dalam PKM yaitu sebagai pendamping, dokumentasi dan membantu pelatihan

Persiapan materi dan media yang akan digunakan dalam kegiatan PKM yaitu Laptop, LCD, Leafet, powerpoint 


\section{Pelakasanaan}

Kegiatan PKM dilaksanakan dalam bentuk pelatihan dan pendidikan kesehatan pada ibu agar dapat memberdayakan diri dalam pertumbuhan, perkembangan dan psikologi antara ibu dan bayi dengan metode ceramah dan tanya jawab serta pelasanaan simulasi dan latihan pijat bayi. Peserta PKM terdiri dari 16 orang ibu beserta bayinya dengan umur 3-6 bulan

Pelaksanaan kegiatan PKM dilakukan sebanyak 2 (dua) kali yaitu pada tanggal 4 dan 5 agustus 2019 di BPM Suriyanti. Kegiatan penyuluhan I disampaikan oleh 2 pemateri yaitu Dosen DIII Kebidanan dengan rincian materi sebagai berikut : Pijat Bayi dan pengaruh pijat bayi terhadap tumbuh kembang bayi. Penyampaian materi tentang pijat bayi serta pengaruhnya terhadap tumbuh kembang bayi dikarenakan sebagian besar pasien di BPM Suriyanti belum memiliki pengetahuan yang cukup tentang pijat bayi. BPM Suriyanti dikenal dengan BPM yang menerima layanan "Baby Spa", kebanyakkan pasien membawa bayinya untuk dilakukan pijat bayi karena mengikuti trend, ajakan kerabat/teman, serta jika bayi memiliki keluhan.

Sedangkan kegiatan II yaitu diadakan pelatihan pijat bayi yang dilakukan oleh peserta (ibu dan bayinya) serta dipandu oleh instruktur pijat bayi yang telah bersertifikat yaitu salah satu pemateri Dosen DIII Kebidanan dan Bidan dari BPM Suriyanti.

Pada pertemuan kedua tampak peningkatan jumlah ibu yang ingin mengikuti teknik pijat bayi, hal ini menunjukkan perubahan perilaku dimana ibu sadar akan pentingnya melakukan olah fisik dan psikologi dengan bayinya serta meningkatkan kesadaran ibu tentang pemberdayaan diri agar tetap memberikan kasih sayang kepada bayi melalui sentuhan (pijat bayi). Setelah pelaksanaan latihan stimulasi dan baby gym, ibu dilatih untuk melakukan pemijatan bayi yang dapat memberikan ketenangan bayi. Diakhir sesi beberapa ibu mengajukan pertanyaan, menyampaikan bahwa kendala yang mereka rasakan saat melakukan beberapa teknik karena ibu belum mahir melakukan sendiri dan harapannya agar kegiatan ini dilaksanakan secara berkelanjutan.

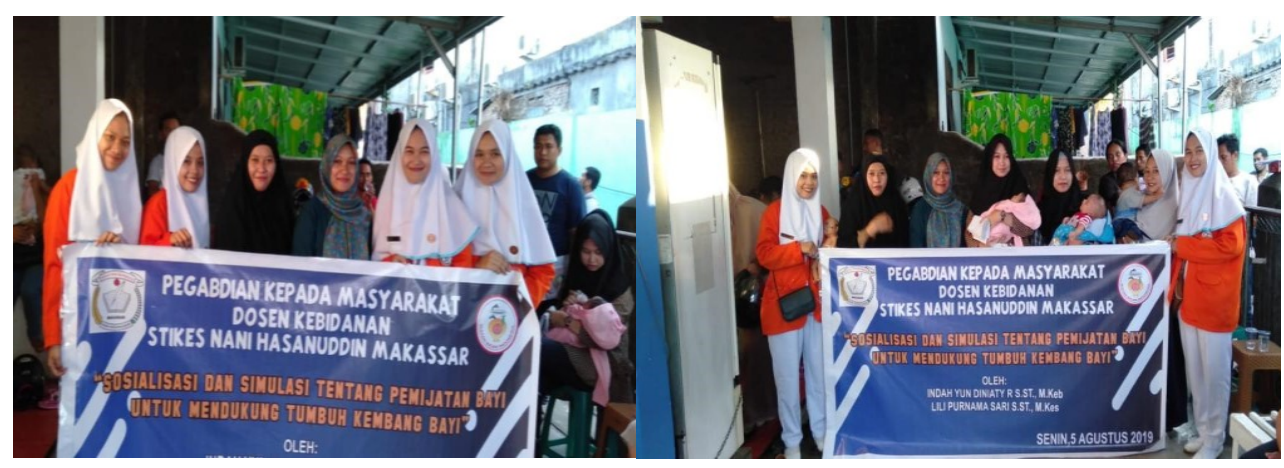

Gambar 1. Penyuluhan PKM di BPM Suriyanti 
[ 68 ] Indah Yun Diniaty Rosidi, dkk / To Maega: Jurnal Pengabdian Masyarakat, Vol.4; No.1; Febrauari 2021

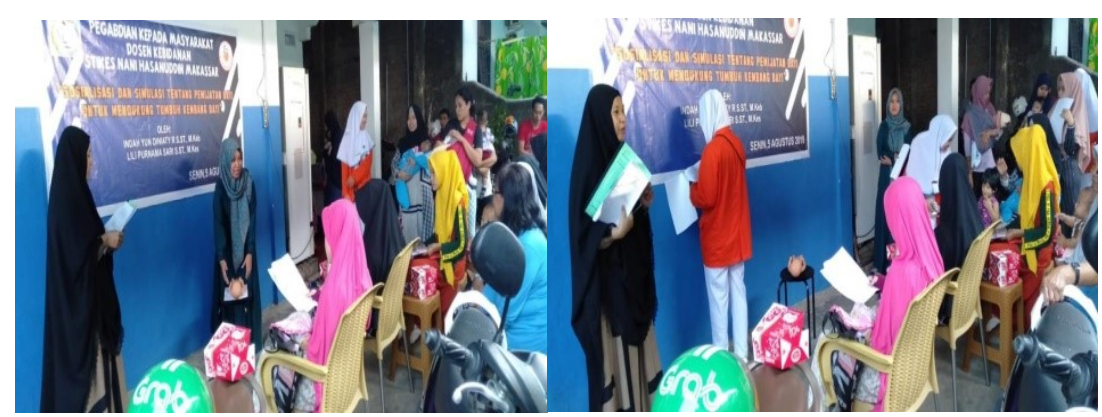

Gambar 2. Penyuluhan PKM di BPM Suriyanti

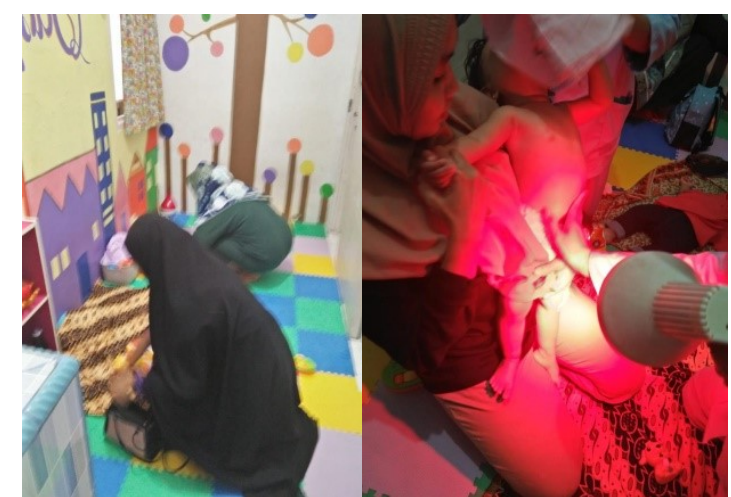

Gambar 3. Pelatihan Pijat Bayi di BPM Suriyanti

3. Evaluasi

Pada tahap evaluasi post test dilaksanakan pada tanggal 19 Agustus 2019, oleh tim PKM menunjukkan Ibu semakin paham tentang pemberian stimulasi pada bayi yaitu melalui pijat bayi. Ibu memberikan sikap yang positif setelah terlaksananya kegiatan PKM. Hal ini terlihat pada gambar bagan distribusi frekuensi pengetahuan Ibu, dimana sebanyak 11 dari 16 orang ibu berpengetahuan baik tentang pijat bayi.

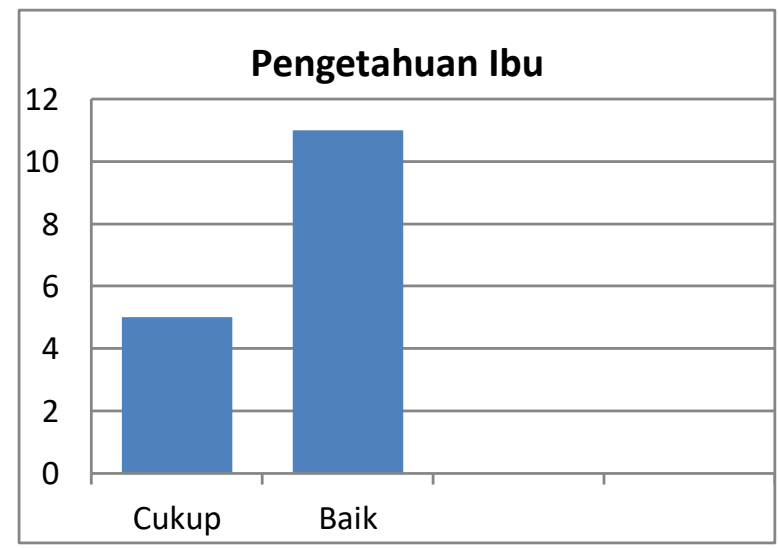

Gambar 4. Distribusi Frekuensi Pengetahuan Ibu

Hasil evaluasi terhadap kemampuan ibu dalam melakukan teknik pijat bayi dan baby gym menunjukkan ibu mampu melakukan secara mandiri dan enjoy bersama bayinya.

CTo Maega / Jurnal Pengabdian Masyarakat. This is an open access article under the CC BY-SA 4.0 license (https://creativecommons.org/licenses/by-sa/4.0/). 


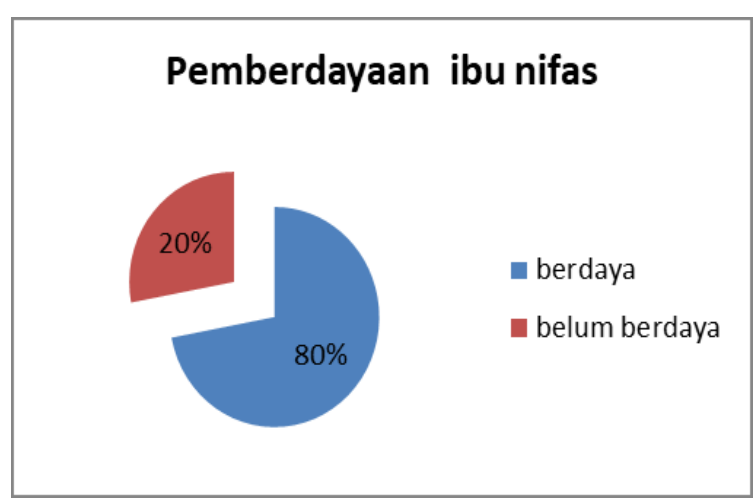

Gambar 5. Diagram Presentasi Pemberdayaan Ibu Nifas

Evaluasi yang dilakukan menujukkan semakin pahamnya ibu tentang pemberian stimulasi dan pijat pada bayi serta mampu melakukannya, sehingga dianggap berdaya dalam pertumbuhan dan perkembangan bayi serta psikologi (80\%) dan belum berdaya dalam pertumbuhan dan perkembangan bayi serta psikologimelalui teknik stimulasi dan pijat bayi (20\%).

\section{Kesimpulan}

Berdasarkan hasil kegiatan pengabdian kepada masyarakat di BPM Suriyanti Kota Makassar maka dapat di peroleh kesimpulan sebagai berikut; Peserta penyuluhan yakni ibu menyusui dapat diberdayakan untuk pemantauan tumbuh kembang bayi dan pemenuhan psikologi bayi, melalui pelatihan stimulasi bayi dan pijat bayi yang baik dan benar. Kami sebagai pelaksana PKM berharap adanya kegiatan lanjutan dari tenaga kesehatan lainnya untuk memberikan health education terkait tumbuh kembang anak dan perlu adanya pemeriksaan DDST di pelayanan setempat agar dapat memantau tumbuh kembang bayi dengan baik.

\section{Ucapan Terimakasih}

Terima kasih penulis sampaikan kepada STIKes Nani Hasanuddin Makassar yang telah memberikan persetujuan dan motivasi sehingga terlaksananya PKM ini, serta BPM Suriyanti dan mahasiswa yang terlibat hingga selesai.

\section{Daftar Pustaka}

Aminarti, D. (2013). Pijat Dan Senam Untuk Bayi \& Balita, Cetakan Ke-1. Yogyakarta : Brilliant Books.

Ariyanti, R., Preharsini, I. A., \& Sipolio, B. W. (2020). Edukasi Kesehatan Dalam Upaya Pencegahan dan Pengendalian Penyakit Hipertensi Pada Lansia. To Maega: Jurnal Pengabdian Masyarakat, 3(2), 74-82.

Dewi, S. (2012). Pijat dan Asupan Gizi Tepat Untuk Melejitkan Tumbuh Kembang Anak. Yogyakarta: Pustaka Baru Press. 
[ 70 ] Indah Yun Diniaty Rosidi, dkk / To Maega: Jurnal Pengabdian Masyarakat, Vol.4; No.1; Febrauari 2021

Dwienda R, Octa, dkk. (2014). Buku Ajar Asuhan Kebidanan Neonatus, Bayi/Balita dan Anak Prasekolah Untuk Para Bidan, Ed.1, Cet. 1. Yogyakarta : Deepublish.

Ferber, S. G., Kuint, J., Weller, A., Feldman, R., Dollberg, S., Arbel, E., \& Kohelet, D. (2002). Massage therapy by mothers and trained professionals enhances weight gain in preterm infants. Early human development, 67(1-2), $37-45$.

Field, T., Diego, M. A., Hernandez-Reif, M., Deeds, O., \& Figuereido, B. (2006). Moderate versus light pressure massage therapy leads to greater weight gain in preterm infants. Infant Behavior and Development, 29(4), 574-578.

Irva, T.S. (2014). Pengaruh Terapi Pijat Terhadap Berat Badan Bayi. Jakarta.

Maharani, S. (2009). Pijat Dan Senam Sehat Untuk Bayi. Yogyakarta: Penerbit Kata Hati.

Minarti, N.M.A. (2012). Pengaruh Pijat Bayi Terhadap Kualitas Tidur Bayi Usia 3-6 Bulan Di Wilayah Kerja Puskesmas II Denpasar Timur Tahun 2012. Jakarta: EGC.

Purnamasari, L., Rosidi, IYD. (2019). Peningkatan Berat Badan Bayi 0-6 Bulan Melalui Tindakan Pemijatan Bayi. Patria Artha Journal of Nursing Science. Vol. 3(2), 124-127.

Rakhmawati, W. (2007). Pijat Bayi. Bandung: Universitas Padjadjaran.

Roesli, U. (2001). Pedoman Pijat Bayi Prematur \& Bayi Usia 0-3 Bulan. Jakarta: Penerbit Pustaka Pembangunan Swadaya Nusantara.

Roesli, U. (2009). Pedoman Pijat Bayi. Jakarta: Penerbit Pustaka Pembangunan Swadaya Nusantara.

Subakti, Y., dkk. (2008). Keajaiban Pijat Bayi \& Balita. Jakarta : Wahyu Media. 